SciTech Clubs for Girls Technical Report

Alyce M. Nogal, Program Coordinator

February 1993

Since January 1992, 9 exhibiti have been constructed by the SciTech Clubs for Girls, which involved 63 girls, ages 10 to 14 . These exhibits are:

-Bubble Shapes by the St. Charles Cadette Girl Scout Troop \#109.

- Density Games by the South Elgin Cadette Girl Scout Troop \#132.

-Electric Fleas by the Warrenville Junior Girl Scout Troop \#305.

-Energy vs. Power by the Aurora Junior Girl Scout Troop \#242.

-The Organ Pipe by the Bartlett Junior Girl Scout Troop \#107.

-Ohm's Law by the Geneva Junior Girl Scout Troop \#401.

-What is Gravity by the Pilsen YMCA girls.

-Insulation at Work by the Algonquin Junior Girl Scout Troop \#303.

-Series vs. Parallel by the Leland Junior Girl Scout Troop \#50.

Refer to the attached for pictures and a map.

The following is a description of each exhibit and the group that built the exhibit. Each group had a minimum of 10 hours of contact time at SciTech with the SciTech Clubs for Girls Program Coordinator. All mentors are female. Each exhibit building experience includes a trip to the hardware store to purchase supplies. After the exhibit is complete, the girls receive certificates of achievement and a SciTech Club Patch.

\title{
Bubble Shapes:
}

The Bubble Shapes exhibit was built by 6 seventh grade girls, of which 5 girls are from St. Charles and 1 girl is from Elgin.

This exhibit illustrates the principle of minimal surface area. It consists of three buckets of soap solution and three different shapes. When the shape is lifted out of the solution, the solution collapses to a shape that requires the least amount of energy to be maintained because it covers the least amount of area.

The girls learned about minimal surface areas from their mechanical engineering science mentor. They learned how bubbles can serve as simple models to help understand how crystals grow, and how scientists have studied bubbles to learn how to build stronger buildings and bridges. The girls also learned general tool use.

\section{Density Games:}

The Density Games exhibit was built by 6 girls in seventh grade and 2 girls in sixth grade, of which 7 girls are from Elgin and 1 girl is from Wayne.

This exhibit illustrates the densities of several materials: lead; aluminum; nylon; copper; wood; and steel. A block of each material was machined to the same size and attached to a rubber ball handle. By lifting the materials, it can be seen that even though the material is the same size, the weight is different due to different densities.

The girls learned about weight and density from their civil engineering science mentor, as well as general tool use.

\section{Electric Fleas:}

The Electric Fleas exhibit was built by 1 girl in seventh grade and 4 girls in sixth grade, of which 3 girls are from Warrenville, 1 girl is from Aurora, and 1 girl is from West Chicago.

\section{MASTER}


This exhibit illustrates the principle of static electricity. There are bits of styrofoam under a clear plastic cover. When the cover is rubbed, the "fleas" are attracted to the charge on the underside of the plastic cover.

The girls learned about electricity, conductors, and charge transfer from their electrical engineering science mentor. They also learned general tool use.

\section{Energy vs. Power:}

The Energy vs. Power exhibit was built by 3 girls in fourth grade, 4 girls in fifth grade, and 1 girl in sixth grade, of which all 8 girls are Latino from Aurora.

This exhibit illustrates the difference between energy and power. A persons energy is used to turn a hand crank, and is converted into electrical energy by a generator. The electrical energy is stored and is used to turn on lights by the flip of a switch.

The girls learned about power and energy from their electrical engineering science mentor. They also learned how to solder a circuit, as well as general tool use.

\section{Organ Pine:}

The Organ Pipe exhibit was built by 10 sixth grade girls, of which 9 are from Bartlett and 1 is from Carol Stream.

This exhibit illustrates how sound waves resonate. By adjusting the position of the pipe and the frequency of the tone, the organ pipe demonstrates where the tone resonates.

The girls learned about sound and air pressure from their mechanical engineering science mentor. They also learned general tool use from a construction mentor.

\section{Ohm's Law:}

The Ohm's Law exhibit was built by 5 sixth grade girls from Geneva.

This exhibit illustrates that voltage is proportional to current times resistance.

The girls learned about voltage, current, and resistance from their electrical engineering science mentor. They learned about the difference between $\mathrm{AC}$ and $\mathrm{DC}$ electricity. The girls had a female journeyman carpenter teach them about shop safety and tool use. They also learned how to solder.

Even though their exhibit is complete, this group of girls has had continued involvement with SciTech. In December they had a behind-the-scenes tour of Chicago's Field Museum of Natural History. They have returned to do some exhibit repair and modification to replace a faulty switch on their exhibit. They have also spoken to our explainer supervisor and may return to volunteer Saturdays as explainers (museum interpreters).

\section{What is Gravity?:}

The What is Gravity exhibit was built by 1 sixth grade girl, 1 seventh grade girl, and 3 eighth grade girls, all were from the Pilsen neighborhood, a Latino community in the city of Chicago.

This exhibit illustrates the principle of gravity by weighting a coke can what it would way on the various planets.

This group of girls came in for an overnight exhibit building experience. They arrived at SciTech at 8:30 a.m. on a Saturday and stayed through until 3:00 p.m. on Sunday. The girls learned about gravity from a mechanical engineering mentor. They had a female journeyman carpenter teach them about shop safety and tool use.

In the evening of their overnight stay, the girls were engaged in activities that would further their experience at SciTech. They had a treasure hunt that used math, science, and the exhibits on the floor to demonstrate that these topics can be fun. They also painted wooden heart necklaces in which they drilled a hole for the chain. The necklace serves as a small momento from their experience and proof that they can use tools.

In November, SciTech took its Discover and Explore program to the Pilsen YMCA. The girls exhibit was on display during that week. The girls attended our reception at the 
Pilsen YMCA and we held a small ceremony for them to receive their certificates of achievement.

\section{Insulation at Work:}

The Insulation at Work exhibit was built by 9 fifth grade girls and 1 sixth grade girl, all were from Algonquin.

This exhibit demonstrates how fiberglass irisulation works in a house.

The girls learned about heat and heat transfer from a mechanical engineer whose thesis work was in heat transfer. They learned about shop safety and tool use from a female journeyman carpenter. They learned about AC electricity while wiring the heat lamps in the exhibit. They also drilled holes in the wooden hearts to make necklaces.

This group of girls will return in March to do exhibit maintenance, and they will schedule a behind the scenes tour at the Chicago Field Museum of Natural History later this Spring.

\section{Series vs. Parallel:}

The Series vs. Parallel exhibit was built by 6 sixth grade girls from Leland, a rural community.

This exhibit demonstrates the difference between connecting a circuit in series and parallel by showing how the brightness of lightbulbs is affected by the connections.

The girls learned about electricity from an electrical engineering science mentor. They learned about shop safety and tool use from a female journeyman carpenter. This group of girls had an additional opportunity. They made a coat rack that hangs in the shop as part of their introduction to tools. The idea behind the coat rack was to give the girls a small project that is real to get them comfortable with the tools. The coat rack hangs in our shop area with the names of the girls who made it, thus providing them with a sense of ownership in their shop area. The girls also drilled holes in the wooden hearts to make necklaces.

\section{DISCLAIMER}

This report was prepared as an account of work sponsored by an agency of the United States Government. Neither the United States Government nor any agency thureof, nor any of their employees, makes any warranty, express or implied, or assumes any legal liability or responsibility for the accuracy, completeness, or usefulness of any information, apparatus, product, or process disclosed, or represents that its use would not infringe privately owned rights. Reference herein to any specific commercial product, process, or service by trade name, trademark, manufacturer, or otherwise does not necessarily constitute or imply its endorsement, recommendation, or favoring by the United States Government or any agency thereof. The views and opinions of authors expressed herein do not necessarily state or reflect those of the United States Government or any agency thereof. 


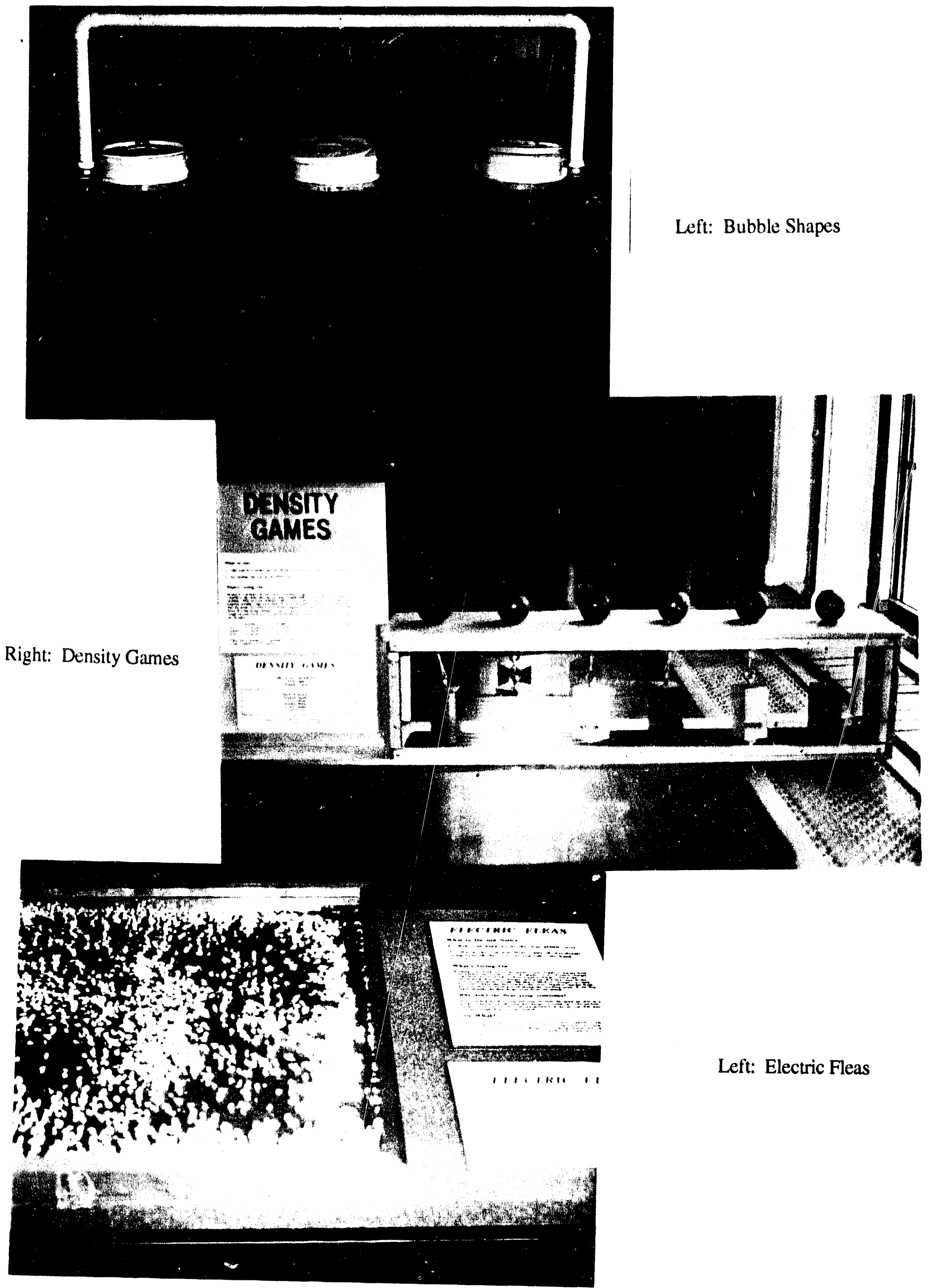




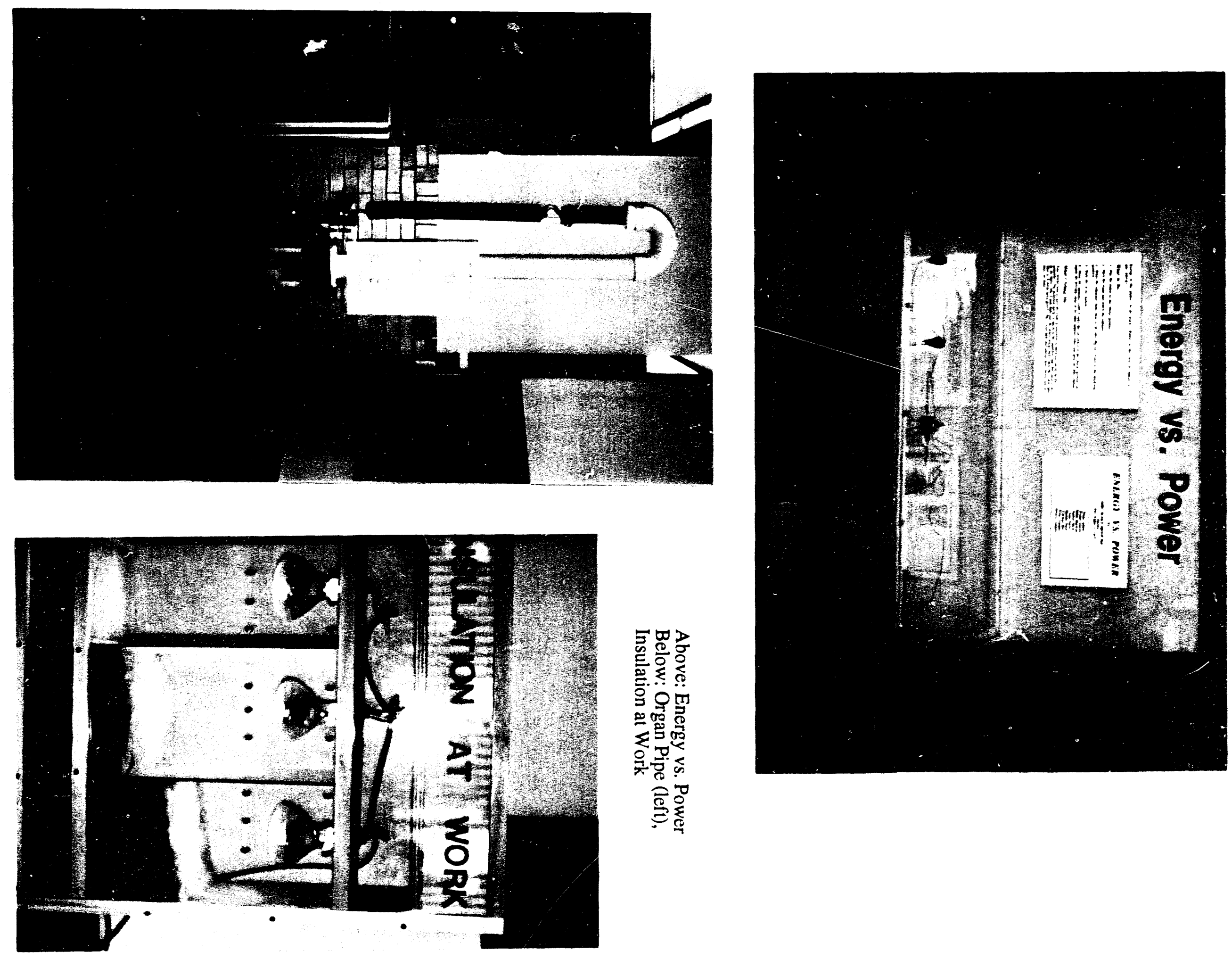




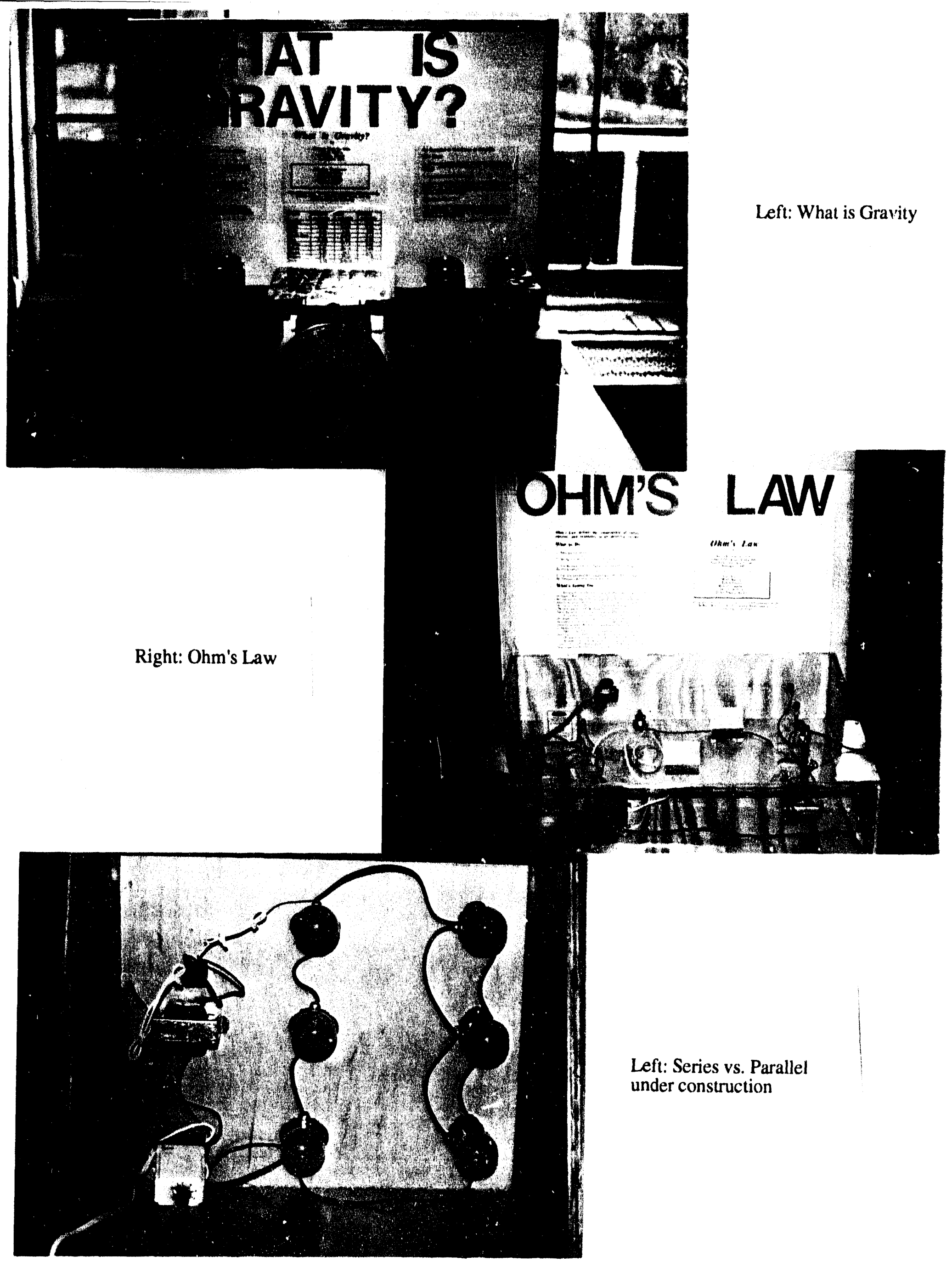




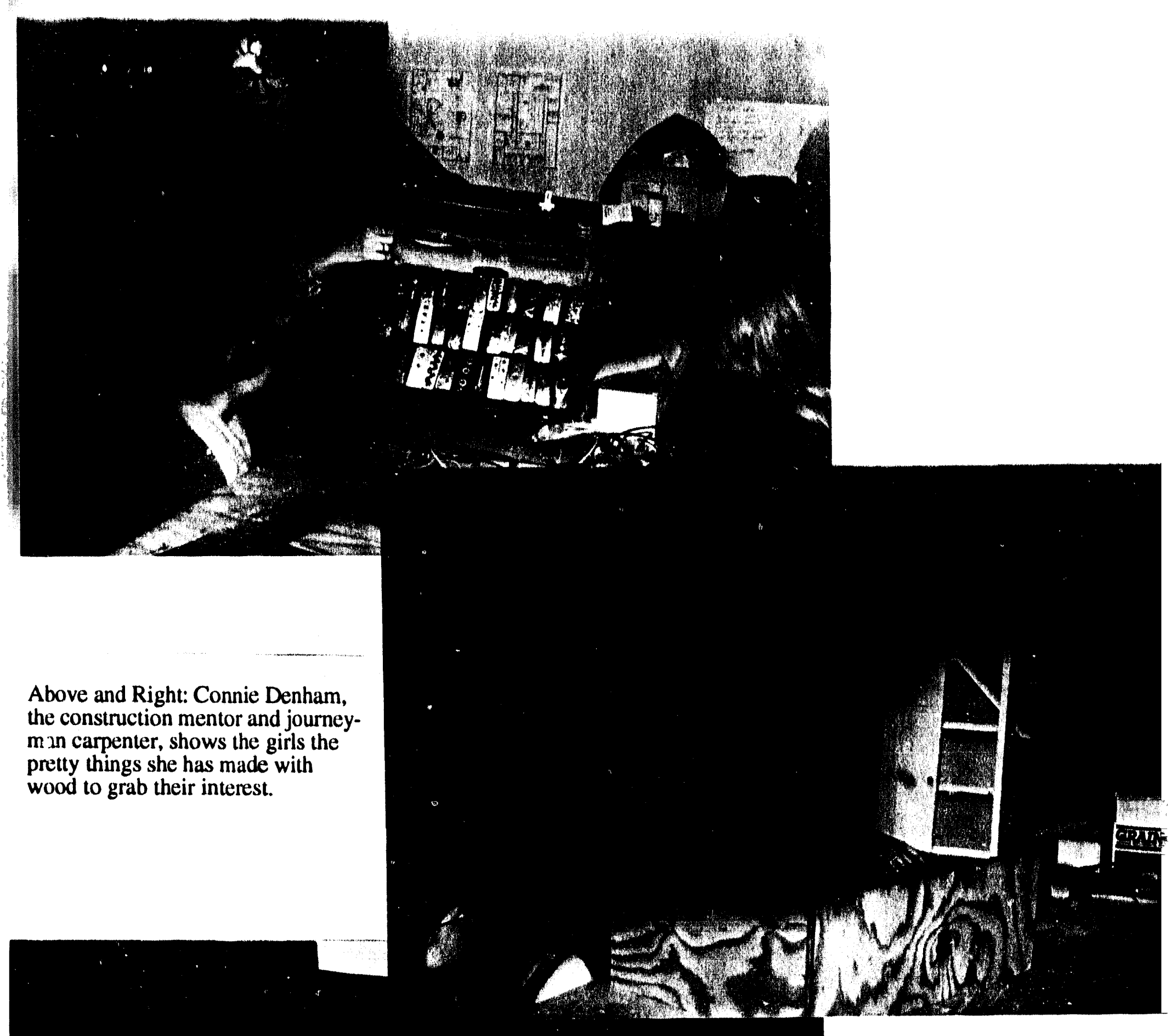

Above and Right: Connie Denham, the construction mentor and journeym in carpenter, shows the girls the pretty things she has made with wood to grab their interest.
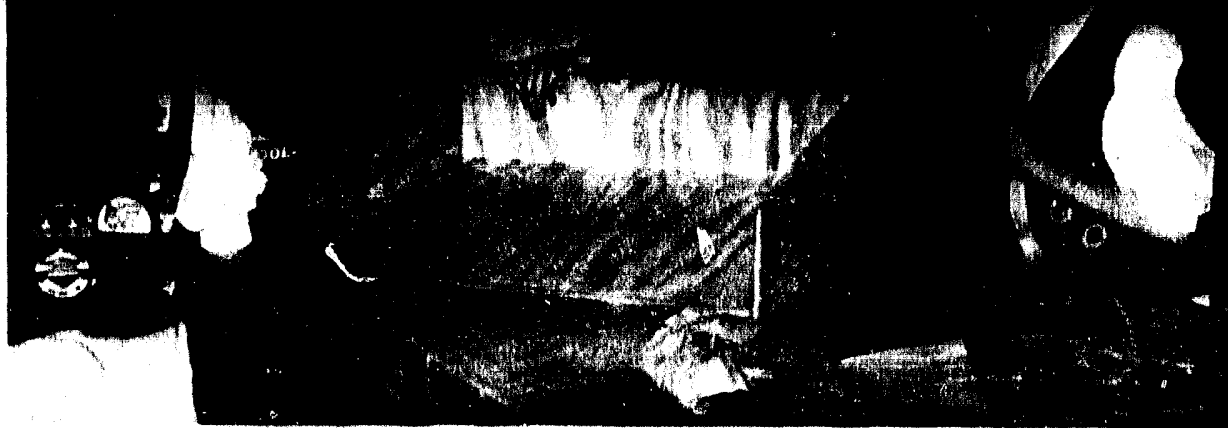

Left: Connie then instructs the girls on tool use and helps them assemble their exhibit. 


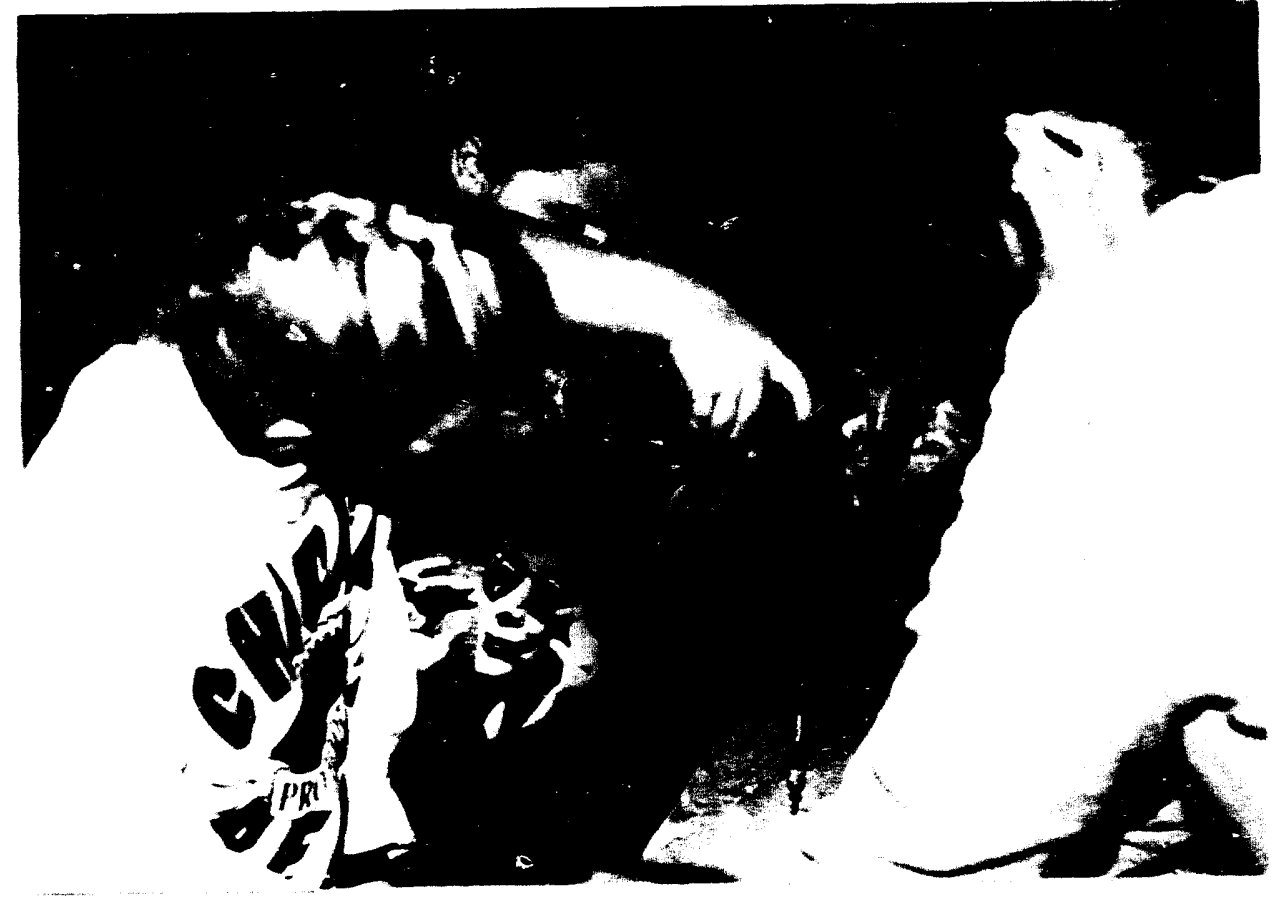

Above: Drilling holes for the coatrack. Below: Drilling holes to make necklaces.

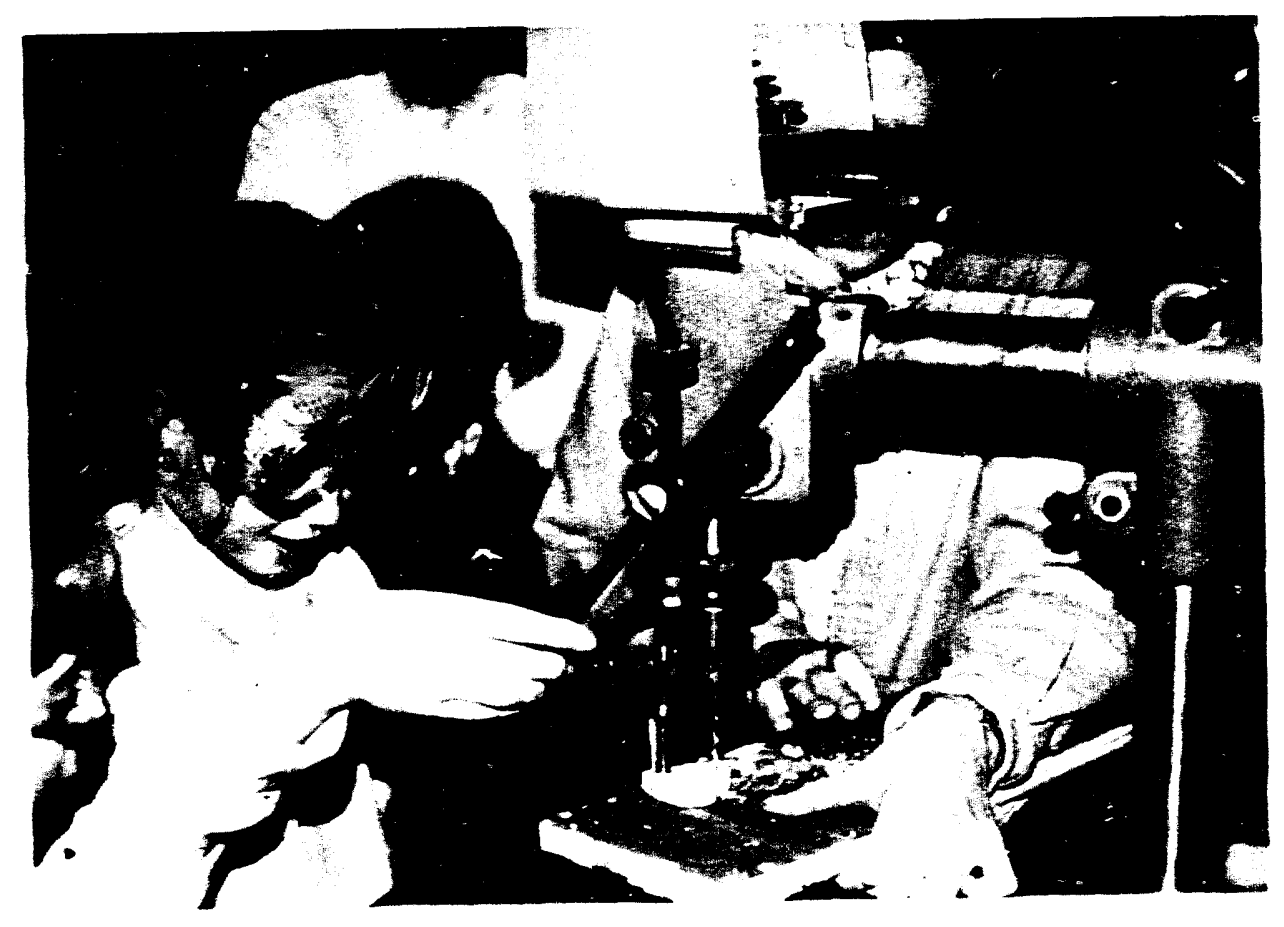

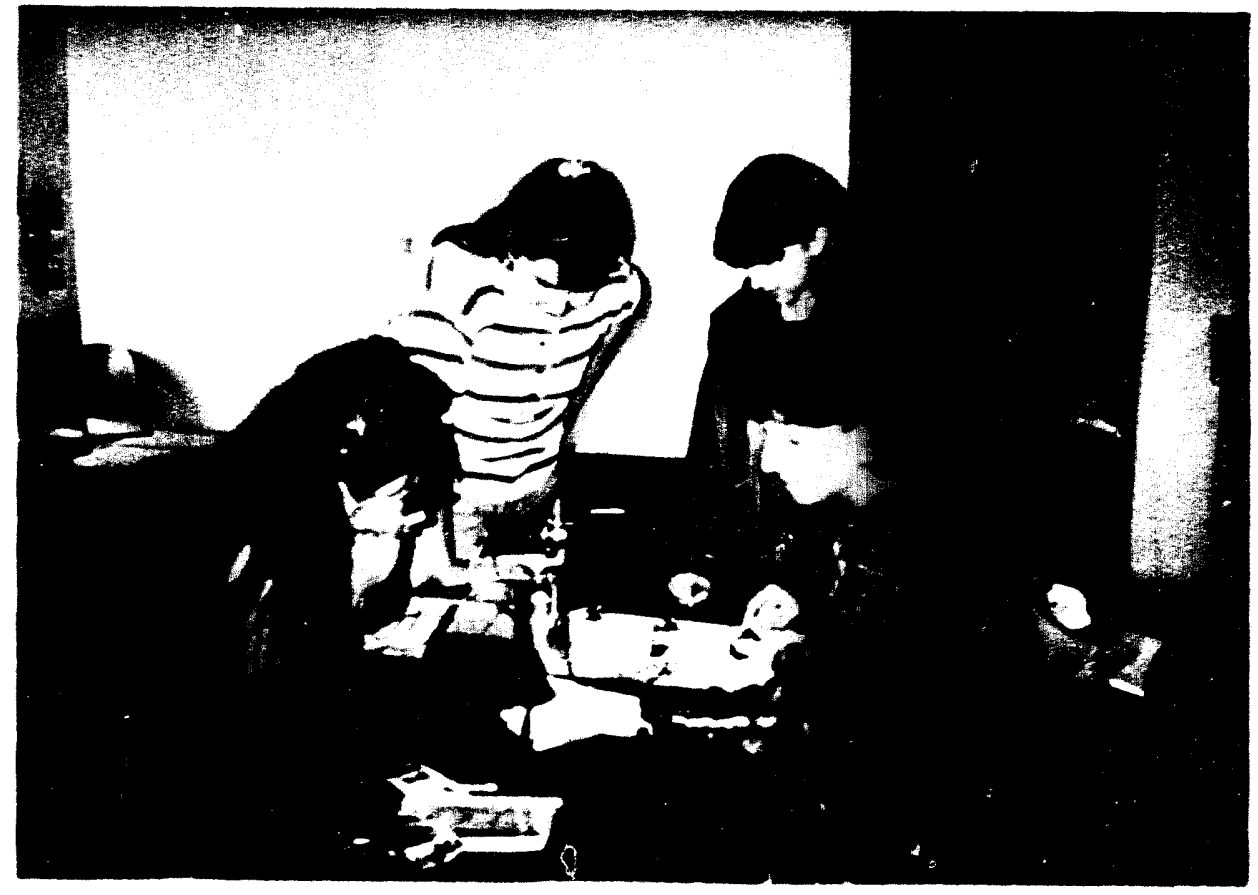

Above: Science mentor with girls for Energy vs. Power Below: Working on Series vs. Parallel.

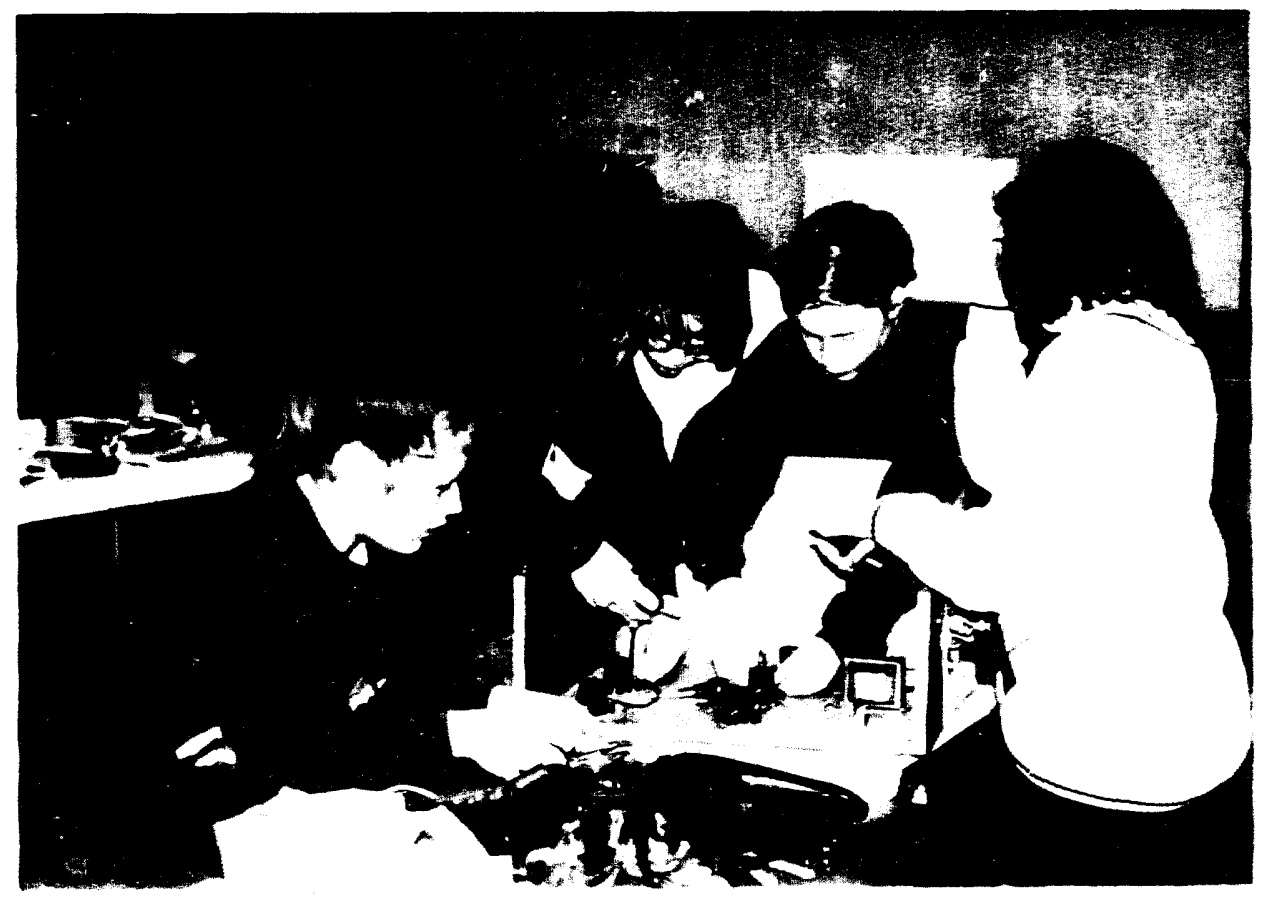


$1 !$
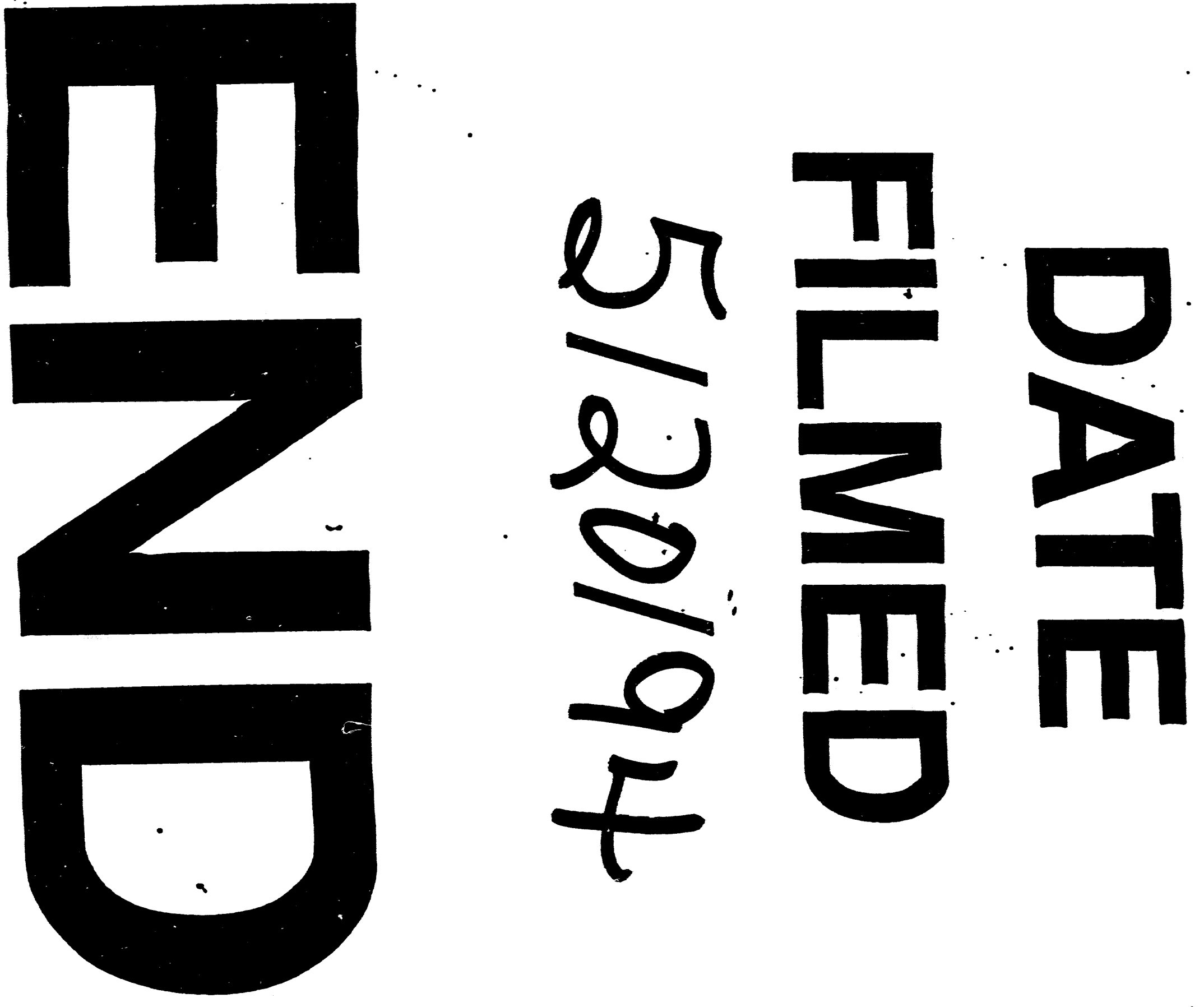

$F$ 
